\title{
Free recall from mixed-language lists by Greek-English and French-English bilinguals
}

\author{
P. D. McCORMACK, C. BROWN, and B. GINIS \\ Carleton University, Ottawa KIS 5B6, Canada
}

\begin{abstract}
Twenty French-English and 16 Greek-English bilinguals were postcued to recall items from one or both of their languages. The usual phenomenon of superior recall of weak-language items was not observed. It was concluded that subjects give rehearsal priority to weak-language items when they are set to recall from both languages.
\end{abstract}

When subjects who are competent in two or more languages are required to recall from mixed-language lists, a disproportionate number of items from the weaker language are observed in their recall protocols. This appears to be a stable phenomenon: Nott and Lambert (1968) report it for bilingual lists, and Tulving and Colotla (1970) observed it in the secondary-memory component of both bilingual and trilingual lists. Finally, McCormack and Novell (1975) observed it as well, as a secondary-memory phenomenon, with trilingual subjects. In all three investigations, the subjects were aware of the requirement to recall in both, or in all three, of their languages. In the present study, a procedure is employed whereby the bilingual is uncertain of the response requirements of the task; that is, on some trials, he is postcued for items from only one of his two languages, and on others, for words from both languages. If, under these conditions, the phenomenon of superior weak-language recall from secondary memory should fail to appear, it may be attributed to a set or strategy factor. On the other hand, should it be observed once more, another explanation must be sought.

\section{METHOD}

The subjects were 36 Carleton University students, 20 English-French bilinguals (Group EF) and 16 English-Greek bilinguals (Group EG). All subjects of Group EF and six of those in Group EG were English-language dominant, whereas the remaining 10 subjects of Group EG had Greek as the dominant language. Dominance was defined according to a modified version of a questionnaire developed by Colletta (1975). Subjects of Group EG were run in subgroups of five, five, three, and three; those of Group EF were made up of subgroups of six, five, five, and four.

The lists were developed from nouns taken from the normative data of Paivio, Yuille, and Madigan (1968), each item having a Thorndike-Lorge (1944) frequency count of 17 or more and imagery, concreteness, and meaningfulness scale values greater than or equal to 3.00 . These words, as well as their translations into French or Greek, were presented to three EG and three

Requests for reprints should be sent to P. D. McCormack, Department of Psychology, Carleton University, Ottawa, Ontario K1S 5B6, Canada. The data presented here are those of the two junior authors and were collected in conjunction with their meeting the requirements for the honors BA degree.
EF judges, all of whom were classmates of the experimental subjects. The judges were then asked to eliminate any words with which they were unfamiliar in either of their two languages. As a result of this procedure, 324 words and their translations into Greek or French were retained, allowing for the construction of 15 mixed-language lists of 18 words, as well as 3 practicetrial lists. In each list, half of the words were from the dominant and half from the weak language of the subject. A word, or its translation, was used only once for any given subgroup of subjects.

The single-trial free recall paradigm was employed for all 15 mixed-language lists. The choice of words for any given list was determined at random for each subgroup of subjects, with the words from the dominant and weak languages alternating. Following the presentation of the 18th item of each list, one of two major types of postcues was introduced. If the experimenter said "both," the subject was required to recall from both languages; if he said "only," the subject would recall from only the designated language. There were, then, three postcuing conditions, with five lists per condition; that is, the subject recalled words from both languages, from the dominant language only, or from the weak language only. The order in which the three types of postcues were presented was random, with the constraints that no one of these be given more than twice in succession and that there be five lists for each. The session, which lasted approximately $1 \mathrm{~h}$, began with three practice trials, one for each type of probe. All materials were presented orally. The interword interval was $2 \mathrm{sec}$, and $2 \mathrm{~min}$ were given for written recall from each list. The interlist interval was $10 \mathrm{sec}$. The subjects were required to recall in the appropriate language in order to be credited with a correct response.

\section{RESULTS AND DISCUSSION}

The Tulving-Colotla (1970) procedure for defining primary and secondary memory was employed. A word was assumed to have been recalled from the secondarymemory store if eight or more other items intervened between its input and output. Nouns with lags of seven or fewer items were considered as having been retrieved from primary memory. An analysis of variance of number of correct responses appropriate for a 2 by 2 by 2 by 2 mixed design was performed on the data. One comparison (GF) was between subjects, that for Groups EG vs. EF. The other three involved withinsubjects evaluations: "both" vs. "only" (BO), dominant vs. weak language (DW), and primary vs. secondary memory (PS). A statistically reliable second-order interaction (BO by DW by PS) was observed $[F(1,34)=$ 
Table 1

Mean Number of Words Recalled for Subjects Under the Various Conditions of the Experiment

\begin{tabular}{lcccccccc}
\hline & \multicolumn{3}{c}{ "Both" } & & \multicolumn{3}{c}{ "Only" } & \\
\cline { 2 - 3 } \cline { 6 - 7 } Memory & $\begin{array}{c}\text { Dominant } \\
\text { Language }\end{array}$ & $\begin{array}{c}\text { Weak } \\
\text { Language }\end{array}$ & Combined & $\begin{array}{c}\text { Dominant } \\
\text { Language }\end{array}$ & $\begin{array}{c}\text { Weak } \\
\text { Language }\end{array}$ & Combined & Overall \\
\hline Primary & 5.22 & 5.64 & 10.86 & 6.86 & 8.08 & 14.94 & 25.80 \\
Secondary & 12.06 & 12.03 & 24.09 & 13.33 & 10.75 & 24.08 & 48.17 \\
Combined & 17.28 & 17.67 & 34.95 & 20.19 & 18.83 & 39.02 & $73.97 *$ \\
\hline
\end{tabular}

$* 73.97 / 270=.27$.

13.66, $\mathrm{p}<.001]$. The appropriate data are shown in Table 1, in which the cell entries indicate the mean number of words recalled per subject for each condition. The mean total number of responses recalled was 73.97 out of a possible 270 words. This proportion of .27 was roughly comparable to that of .32 observed by McCormack and Novell (1975). The difference likely reflects the uncertainty of the response requirements of the present study. The BO by DW by PS interaction simply mirrors the fact that the DW by PS first-order interactions were different for the "both" and "only" conditions. An examination of the data for the "both" conditions leads to the firm conclusion that the phenomenon of better weak-language recall from secondary memory was not observed in this study. This phenomenon, therefore, likely appears only under conditions in which subjects know that they must invariably recall from both languages (McCormack \& Novell, 1975; Nott \& Lambert, 1968; Tulving \& Colotla, 1970). Perhaps, under such conditions, subjects choose to rehearse the weak-language items disproportionately with respect to words from the dominant language, whereas, in the setting of the present experiment, they are more likely to afford equal processing time to each language.

McCormack and Novell (1975) report better recall from primary memory for dominant- than for weaklanguage items. An examination of the data of the "both" condition reveals that this was not the case in the present study. It appears that when subjects are certain of the response requirements of the task (e.g., McCormack \& Novell, 1975), they choose to "dump" dominant-language items from the primary store; they then get on with the task of searching secondary memory for as many as possible of the weak-language items, which, presumably, have received rehearsal priority. Another finding of the present investigation was that, under the "only" condition, there were more weak- than dominant-language items recalled from primary memory but fewer relative to the dominant language from secondary memory (see Table 1). It is not particularly surprising that, when subjects are recalling from one language only, their secondarymemory recall is best for items from the dominant language. This finding is similar to the observation that more dominant- than weak-language items are recalled from unilingual lists (McCormack \& Novell, 1975; Nott \& Lambert, 1968; Tulving \& Colotla, 1970). Perhaps the subjects make effective use of "forget instructions" for weak-language items (i.e., Bjork, 1970). The primarymemory findings of the present study are more difficult to interpret. A comparison of Groups EG and EF revealed that recall from the primary store was best for Group EG, whereas Group EF subjects exhibited superior secondary-memory recall. This GF by PS interaction $[F(1,34)=14.55, p<.001]$ raises the question of whether different memory storage systems have capacities that are invariant across language groups. In the present investigation, the main effect of primaryvs. secondary-memory recall was statistically reliable $[\mathrm{F}(1,34)=82.19, \mathrm{p}<.001]$, with more items recalled from secondary than from primary memory (see Table 1). The same phenomenon has been observed by numerous other investigators (e.g., McCormack \& Novell, 1975). Finally, more items were recalled from a given language under the "only" than under the "both" condition $[F(1,34)=10.72, p=.002]$ (see Table 1). This could be attributed to the likelihood that interlanguage output interference would be negligible under conditions of recall of the one language.

\section{REFERENCES}

BJork, R. A. Positive forgetting: The noninterference of items intentionally forgotten. Journal of Verbal Learning and Verbal Behavior, 1970, 9, 225-268.

Colletta, S. P. "Same-different" judgments with bilinguals. Unpublished master's thesis, Carleton University, 1975.

McCormack, P. D., \& Novell, J. A. Free recall from unilingual and trilingual lists. Bulletin of the Psychonomic Society, 1975, 6, 173-174.

NotT, C. R., \& LAmbert, W. E. Free recall of bilinguals. Journal of Verbal Learning and Verbal Behavior, 1968, 7, 1065-1071.

Paivio, A., Yuille, J. C., \& Madigan, S. A. Concreteness, imagery, and meaningfulness values for 925 nouns. Journal of Experimental Psychology, 1968, 76(1, Pt. 2).

Thorndike, E. L., \& Lorge, I. The teacher's word book of 30,000 words. New York: Columbia University Press, 1944.

Tulving, E., \& Colotla, V. A. Free recall of bilingual lists. Cognitive Psychology, 1970, 1, 86-98.

(Received for publication August 28, 1979.) 